\title{
Kesesuaian ASEAN Agreement on Transboundary Haze Pollution (AATHP) dengan Norma ASEAN
}

\author{
Miftahul Choir \\ 2016330170 \\ Mahasiswa Ilmu Hubungan Internasional, Fakultas Ilmu Sosial dan Ilmu Politik \\ Universitas Katolik Parahyangan
}

\begin{abstract}
Haze pollution is one of the challenges that ASEAN has faced from several decades. Indonesia, as the country that hold most of the tropical forestry in the region, occasionally had forest fire that caused by either climate change or man-made deforestation. Forest fire that occurred in Indonesia consequences at thick haze in neighboring countries Malaysia and Singapore skies, which madeboth countries securitize as it was threatening the lives of their people. Thus, in order to tackle the problem, on 2002, ASEAN released an environmental protocol named ASEAN Agreement of Transboundary Haze Pollution $(A A T H P)$. However, the questions raises whether the enviromental protocol fit to the ASEAN Way. This paper argues that AATHP is not violating any of ASEAN norms and value, as it is not a fully legally binding protocol. Constructivism approach will be used as a tool to analyse how AATHP comply to ASEAN way.
\end{abstract}

Keywords: Norms, values, enviromental protocol, ASEAN Way

\section{Pendahuluan}

Kabut asap merupakan salah satu isu utama dalam Asosiasi Negara di Asia Tenggara (ASEAN). Tiap tahun, isu kabut asap selalu terjadi, terutama pada musim-musim tertentu dimana lahan gambut yang terletak di beberapa wilayah mudah terbakar dan juga aktivitas manusia yang sengaja membakar hutan tersebut. Kebakaran hutan yang semulanya hanya berlangsung di suatu negara kemudian terbawa ke negara lain, hal inilah yang menjadi permasalahan di ASEAN yaitu kabut asap lintas batas. Sehingga dalam penangannya dibutuhkan pula upaya kolektif yang terinstitusikan dalam kerangka ASEAN.

Kabut asap di Asia Tenggara umumnya terjadi di Indonesia pada musim kering yang melanda negara tersebut di bulan Juni-Agustus. Musim kering ini mengakibatkan lahan gambut yang terkonsentrasi di Sumatra, Papua, dan

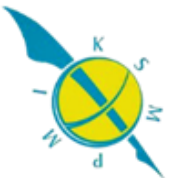


Kalimantan mudah terbakar. Akibatnya adalah asap yang dibawa oleh kebakaran hutan ini terbawa ke negara tetangga Malaysia dan Singapura. Sementara kebakaran hutan yang terjadi di Kalimantan, pulau dimana sebagian besar hutan Indonesia berlokasi, mengakibatkan asap terbawa hingga beberapa pulau di Filipina. Fenomena cuaca yang berubah dalam beberapa tahun terakhir juga memperparah kebakaran hutan, terutama pada tahun 2015 lalu, dimana kabut asap paling parah dalam waktu sepuluh tahun terakhir. El Nino yang menimpa kawasan Asia Tenggara pada saat itu mengakibatkan musim kering berkepanjangan dan mengakibatkan musim hujan yang telat datang. ${ }^{1}$

Fenomena tahunan ini berakibat cukup fatal bagi negara-negara yang terkena dampak, baik secara politik maupun dampak lingkungan dan ekonomi. Singapura dan Malaysia selaku negara tetangga Indonesia dan merupakan negara terdekat dengan Pulau Sumatra, mengalami akibat paling besar dari kabut asap yang dibawa Indonesia. Singapura dan Malaysia masing-masing mengalami kerugian sebesar $\$ 700$ juta pada saat kabut asap yang cukup parah melanda kawasan ini pada tahun 2015 lalu. ${ }^{2}$ Dana kerugian tersebut dialokasikan pemerintah masing-masing untuk mengatasi masalah kesehataan yang dialami oleh penduduk mereka akibat kabut asap yang menyelimuti kota-kota di kedua negara tersebut. Selain itu, beberapa sektor seperti pariwisata dan penerbangan juga dirugikan akibat kabut asap ini. Untuk Indonesia, selaku negara yang mengalami kebakaran hutan, kabut asap berdampak lebih besar kepada masyarakat dan perekonomian negara. Selain merusak kesehatan manusia, kabut asap ini juga menghentikan aktivitas ekonomi dan sekolah di beberapa kawasan di Indonesia. Secara politis, kabut asap ini memberi tekanan internasional pada Indonesia untuk segera menyelesaikan kasus

\footnotetext{
1 "Indonesia Fire's and Haze Crisis," World Bank, diakses pada 14 November 2017, http://www.worldbank.org/en/news/feature/2015/12/01/indonesias-fire-and-haze-crisis.

2 Olly Barratt, "Haze episode cost Singapore estimated S\$700m last year: Masagos," Channel NewsAsia, 16 Maret 2017, diakses pada 14 November 2017, http://www.channelnewsasia.com/news/singapore/haze-episode-cost-singapore-estimated-s700m-last-year-masagos-8147924.
}

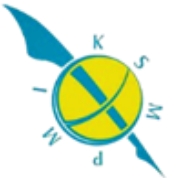


ini, tekanan tidak hanya datang dari kawasan Asia Tenggara tetapi juga dari dunia internasional secara luas.

Untuk mengatasi permasalahan ini, ASEAN telah memiliki beberapa upaya yang terinstitusionalisasikan. Umumnya, upaya ini disponsori oleh Singapura selaku negara kota yang tiap tahunnya terselimuti oleh kabut dari Indonesia sehingga menghentikan aktivitas ekonomi. Upaya ASEAN dimulai di tahun 1997, ketika kabut asap terbesar yang terjadi di kawasan Asia Tenggara melahirkan sebuah Regional Haze Action Plan (RHAP) Di tahun 2003, ASEAN akhirnya memiliki kerangka kerja untuk mengatasi kebakaran hutan, yaitu ASEAN Agreement Transboundary on Haze Pollution (AATHP). Kerangka kerja ini merupakan kerja sama mengikat pertama yang diresmikan di ASEAN dan menjadi acuan dalam penangan kabut asap.

Dalam menyelesaikan kasus atau sengketa yang terjadi di kawasan Asia Tenggara, ASEAN merujuk pada norma yang dianut organisasi ini yaitu noninterefensi, musyawarah mufakat untuk mencapai hasil konsensus yang tidak merugikan satu pihak, dan diplomasi informal dalam menyelesaikan masalah regional. Hal ini terlihat dari ASEAN yang cenderung menghindari keterlibatan langsung dalam masalah domestik negara walaupun berdampak pada kawasan. Latar belakang dari cara kerja ASEAN ini kemudian menimbulkan pertanyaan: bagaimana AATHP dapat berfungsi dalam norma yang dianut oleh ASEAN? Apabila kesepakatan ini bersifat mengikat, maka memiliki kekuatan untuk menentukan kebijakan yang harus diambil negara penandatangan dan memberi sanksi apabila tidak mematuhi aturan tersebut. Apabila melihat di atas kertas, AATHP jelas merupakan pelanggaran dalam norma non-interferensi, dimana ASEAN telah memasuki ranah domestik negara. Dengan hadirnya norma tersebut juga kemudian mempertanyakan apakah AATHP sungguh berhasil dalam menyelesaikan kasus kabut asap di Asia Tenggara.

\section{Kerangka Teori}

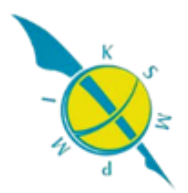


Teori konstruktivisme akan digunakan dalam menganalisis kesesuaian AATHP dengan norma-norma yang dianut oleh ASEAN. Teori ini berpandangan bahwa nilai, identitas, serta norma penting dalam hubungan internasional serta membentuk bagaimana interaksi antara dua negara berlangsung. ${ }^{3}$ Dalam tulisan ini akan dieksplorasi bagaimana pengaruh norma ASEAN yang terinstitusi dalam Treaty of Amity and Cooperation (TAC) memengaruhi pembentukan AATHP. Pandangan Martha Finnemore yang menyatakan bahwa makna dan nilai yang terinstitusi dalam organisasi internasional dan dapat memengaruhi kepentingan serta preferensi juga akan digunakan sebagai alat untuk menganalisis sikap negara anggota ASEAN dalam menyikap AATHP. ${ }^{4}$

\section{Pembentukan AATHP}

Pembentukan AATHP berangkat dari serangkaian kasus kebakaran hutan yang melanda kawasan ini. Meskipun sebelumnya telah disebutkan bahwa kesepakatan ini bermula pada krisis yang terjadi di tahun 1997, beberapa tahun sebelumnya telah ada kesepakatan minor mengenai penanganan serta pengakuan terhadap adanya masalah kabut asap ini terutama di awal tahun 1990. Pembentukan kesepakatan kecil mengenai kabut asap ini didasari pada kenyataan bahwa kasus ini bersifat transnasional sehingga tidak dapat diselesaikan oleh satu negara saja. ${ }^{5}$ Terutama bagi Singapura yang menyadari langkah mitigasi hanya berfungsi untuk mengurangi dampak dari kasus ini tetapi tidak dapat berfungsi dalam mengurangi intenstitas asap dari Indonesia.

3 Paul Viotti dan Mark Kauppi, "Constructivist Understanding," dalam International Relations Theory (New York: Pearson, 2010).

${ }^{4}$ Yu Tai Tsai, "The Emergence of Human Security: A Constructivist View," International Journal of Peace Studies 14, no. 2 (2009): diakses pada 14 November 2017, https://www.gmu.edu/programs/icar/ijps/vol14_2/TSAI\%20-\%2014n2\%20IJPS.pdf.

${ }_{5}^{5}$ Daniel Heilmann, "After Indonesia's ratification: ASEAN Agreement on Transboundary Haze Pollutions and Its Effectiveness as a Regional Enviromental Governance," Journal of Current Southeast Asia Affairs 34, no. 3 (2015), diakses pada 14 November 2017, https://journals.sub.uni-hamburg.de/giga/jsaa/article/download/907/914.

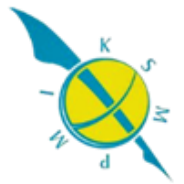


Pengakuan ASEAN terhadap terjadinya kasus kabut asap lintas batas dimulai pada tahun 1985, ketika dalam rentang tiga tahun sebelumnya terdapat 3.2 juta hektar hutan terbakar. Menyusul fenomena tersebut, ASEAN membuat sebuah kesepakatan mengenai perlindungan alam Agreement on the Conservation of Nature and Natural Resources yang didalamnya mengatur mengenai upaya untuk mengurangi polusi udara yang diakibatkan oleh perusakan hutan baik secara alami atau akibat aktivitas manusia. Kesepakatan ini merupakan pertama kalinya ASEAN memiliki sebuah kerangka kerja sama lingkungan yang bersifat mengikat, walaupun pada kenyataannya kesepakatan tersebut tidak terimplementasikan hingga saat ini. Beberapa alasan yang membuat kesepakatan ini tidak kunjung terealisasikan adalah kurangnya daya teknis serta ahli sehingga hal tersebut membuat beberapa negara ASEAN belum meratifikasi kesepakatan tersebut. ${ }^{6}$

Dari kesepakatan tersebut, muncul kesepakatan-kesepakatan yang mengkonstitusikan penanganan masalah kabut asap lintas bantas. Diantaranya adalah Kuala Lumpur Accord on Environment and Development di tahun 1990 dan Singapore Resolutions on Environment and Development. Baru di tahun 1994, ASEAN memiliki sebuah kesepakatan yang secara spesifik membahas isu kabut asap transnasional. Sebelumnya, kerja sama ASEAN mengenai masalah kabut asap hanya sebatas penyelenggaraan lokakarya yang diadakan di Balikpapan di tahun 1992 dan pertemuan level menteri yang akhirnya membawa ASEAN menuju pembentukan langkah kongkrit dalam menyelesaikan masalah kabut asap lintas batas. Melalui serangkaian kerja sama tersebut, ASEAN mulai membawa isu kabut asap lintas batas ke dalam topik pertemuan informal antar negara dan akhirnya di tahun 1994 menghasilkan ASEAN Cooperation Plan on Transboundary Pollution.

\footnotetext{
${ }^{6}$ Rachelle Erlyn Macarlyan (2013). The Southeast Asian politics of natural resource use: impacts on food and health inequalities. In: APSA 2013: Australian Political Studies Association Annual Conference 2013, Perth, WA, Australia, (1-16). 30 September-1 $\begin{array}{llllll}\text { October, 2013. } & \text { Diakses pada } 14 & \text { November } & 2017 .\end{array}$ https://espace.library.uq.edu.au/view/UQ:32837.
} 
Di tahun 1997, terjadi sebuah kabut asap yang cukup parah di ASEAN sehingga mengharuskan para negara anggota untuk menyusun kerangka kerja yang lebih kongkrit lagi dalam menyelesaikannya. Di antara bulan Juli dan November tahun 1997, diperkirakan sebanyak 45,000 km² hutan terbakar di Kalimantan dan Sumatra. ${ }^{7}$ Kebakaran hutan mengakibatkan kerugian bagi Singapura dan Malaysia masing-masing sebesar \$0.4 trilliun. Kondisi diperparah juga oleh krisis ekonomi yang sedang melanda Asia Tenggara pada saat itu, sehingga membuat daya beli masyarakat untuk membeli peralatan pengamanan terhadap kabut semakin rendah sehingga dampak kesehatan semakin sulit teratasi.

Dari fenomena itulah di tahun yang sama ASEAN membentuk Regional Haze Action Plan (RHAP). RHAP ini mengkonstitusikan langkah bersama negara anggota ASEAN dalam rangka menyelesaikan masalah kabut asap. Tujuan dari program ini adalah untuk mengatasi kebakaran hutan dengan cara mengimplementasikan manajemen serta pengawasan yang lebih baik, membentuk sistem mekanisme pengawasan serta meningkatkan kapabilitas regional dalam mengatasi kebakaran hutan. ${ }^{8}$ Program ini juga memberi mekanisme pembagian kerja lebih jelas dibanding kesepakatan sebelumnya. Dalam kesepakatan ini, Malaysia berada di garis depan dalam langkah prevensi, Singapura dalam pengawasan, serta Indonesia dalam langkah mitigasi. ${ }^{9}$ Berbeda dengan kesepakatan sebelumnya, RHAP bersifat soft law dan tidak membutuhkan ratifikasi seperti yang tertuang di Vienna Convention on the Law and Treaties (VLCT) dan program ini bergerak berdasarkan norma dan nilai yang dianut oleh negara anggota ASEAN yaitu kesukarelaan, tidak mencari kesalahan, serta membantu sesuai kapabilitas yang dimiliki. Akan tetapi, justru karakteristik seperti itu yang menyulitkan

\footnotetext{
7 Angelika Heil, "The 1997-98 Air Pollution Episode in Southeast Asia Generated by Vegetation Fires in Indonesia," International Forest and Fire News, no. 23 (2000), diakses pada 14 November 2017, http://www.fire.uni-freiburg.de/iffn/country/id/id_32.htm.

${ }^{8}$ Ibid, 3.

${ }^{9}$ Yang Razali Kassim, "A Haze Free ASEAN: Will the Vision Go Up in Smoke?", diakses pada $20 \quad$ November 2017, https://www.rsis.edu.sg/wpcontent/uploads/2014/07/CO13131.pdf.
} 
keberlanjutan dari implementasi RHAP, hingga akhirnya disempurnakan dalam ASEAN Agreement on Transboundary Haze Pollution (AATHP).

Menyusul kegagalan RHAP, Brunei, Malaysia, Indonesia, dan Singapura terus melanjutkan kerja sama dalam rangka menyelesaikan kabut asap lintas batas ini melalui 7th Joint Meeting of the Working Groups for the Sub-Regional FireFighting Arrangements for Sumatra and Kalimantan. Dari kerja sama tersebut, akhirnya dibentuklah ASEAN Agreement on Transboundary Haze Pollution (AATHP) di tahun 2002. Akan tetapi, kesepakatan ini baru aktif di tahun 2003 setelah Thailand menjadi negara ke-6 yang meratifikasi kesepakatan ini. Kesepakatan ini di atas kertas dibuat lebih mengikat dibanding kesepakatan sebelumnya dengan menyatakan beberapa hak dan kewajiban dari negara yang meratifikasi perjanjian ini. ${ }^{10}$ Kesepakatan ini memang menjadi acuan dari kebijakan negara-negara ASEAN dalam memformulasikan kebijakan yang terkait dengan manajemen hutan. Akan tetapi, Indonesia selaku negara terbesar penyumbang asap dari kebakaran hutan baru meratifikasi kesepakatan ini di tahun 2015, sehingga butir-butir hak dan kewajiban yang tertuang di AATHP ini tidak dapat mengurangi intensitas kabut asap dikarenakan negara yang terlibat langsung belum meratifikasi dan ASEAN tidak dapat dapat memaksa Indonesia untuk meratifikasi kesepakatan tersebut.

\section{Kesesuaian Norma ASEAN dengan AATHP}

Ketika didirikan pada tahun 1967 melalui Deklarasi Bangkok, ASEAN memiliki beberapa nilai dan norma yang menjadi identitas kolektif dari para negara anggotanya. Norma tersebut adalah proses pembuatan keputusan yang melalui konsultasi informal sehingga menemukan keputusan yang bersifat konsensus, kedaulatan yang setara, tidak menggunakan paksaan, non-interferensi, serta diplomasi dalam menyelesaikan sengketa atau kasus yang ada di kawasan. Norma-

\footnotetext{
${ }^{10}$ Melda Kamil Ariadno, "Haze Pollution in ASEAN," Journal of Sustainable Development Law and Policy 2, no. 1 (2013).
}

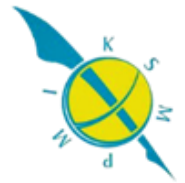


norma tersebut berangkat dari identitas yang dimiliki oleh lima negara pendiri ASEAN, terutama Indonesia dan Malaysia. Prinsip domestik kedua negara tersebut yaitu musyawarah mufakat dan gotong-royong dibawa ke dalam tingkat ASEAN ke dalam bentuk konsensus, kesetaraan, dan tanpa paksaan. ${ }^{11}$ Norma yang terinstitusikan dalam Treaty of Amity and Cooperation (TAC) ini menjadi landasan ASEAN untuk menjaga perilaku dari tiap negara serta mencapai stabilitas regional.

Apabila mengacu dari norma-norma tersebut, AATHP di atas kertas telah melanggar prinsip-prinsip yang dianut oleh ASEAN. Sebuah kesepakatan mengikat dan menginstitusikan negara partisipannya untuk mematuhi hal-hal tertentu dan memasuki ranah kebijakan domestik tidak sesuai dengan prinsip non-interferensi serta menghindari penggunaan paksaan. Dalam pasal 2 TAC disebutkan bahwa prinsip non-interferensi bertujuan untuk menghormati kedaulatan, hubungan baik dalam kerja sama, serta menjaga privasi masalah domestik. Prinsip ini pula yang membuat ASEAN hingga tahun 1992 baru memiliki satu kesepakatan mengikat yang berisi himbauan untuk memberi bantuan teknis dan pendanaan.

Mengenai keterikatan suatu negara terhadap hukum internasional, terdapat dua ikatan yaitu secara politis dan secara hukum. AATHP lebih tepat dikatakan sebagai sebuah kombinasi antara aturan yang bersifat mengikat secara hukum dan juga mengikat secara politis. Keterikatan secara hukum melalui VLCT didefinisikan sebagai aturan yang berisi kewajiban yang perlu ditaati oleh negara partisipan, sanksi juga perlu diterapkan melalui mekanisme hukum dan memerlukan konsen dari pihak terkait. ${ }^{12}$ Sementara aturan dikatakan mengikat secara politis ketika pihak terkait harus menyepakati sebuah aturan secara konsensus dan apabila terdapat

\footnotetext{
${ }^{11}$ Roda Mushkat, "Constructivist Construction of International Enviromental Governances Regimes - The Southeast Asia Context," Merlbourne Journal of International Law 15, no. 1 (2014), diakses pada 21 November 2017, http://www.austlii.edu.au/au/journals/MelbJIL/2014/8.html.

${ }^{12}$ Daniel Bodansky, Legally Binding versus Non-Legally Binding Instruments (August 31, 2015). Forthcoming in: Scott Barrett Carlo Carraro and Jaime de Melo, eds., Towards a Workable and Effective Climate Regime, VoxEU eBook (CEPR and FERDI).
}

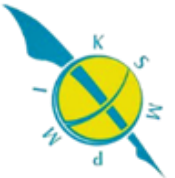


pelanggaran masih dapat dinegosiasikan melalui aktivitas politik. ${ }^{13}$ Hal ini sangat lazim ditemukan dalam perjanjian-perjanjian internasional yang mengatur masalah lingkungan.

AATHP dapat menjadi tidak dapat sepenuhnya menjadi sebuah kesepakatan yang bersifat mengikat secara hukum karena negara anggota ASEAN masih harus mematuhi TAC selaku hukum lebih tinggi serta lebih lama berlaku di ASEAN. Akibat dari itulah, AATHP tidak dapat dikatakan melanggar nilai dan norma seperti non-interferensi, menghindari penggunaan paksaan atau norma lain ASEAN baik yang tertulis maupun tidak tertulis. Hal ini dapat dibuktikan melalui implementasi dari AATHP terutama melihat tidak ada paksaan untuk Indonesia langsung meratifikasi serta substansi kesepakatan ini yang mengandung elemen obligasi, presisi, serta delegasi yang lemah dan belum dapat dikategorikan sebagai hard law. ${ }^{14}$

Secara obligasi atau tingkat keterikatan aktor terhadap suatu hukum internasional, AATHP mencapai tingkat legalitas karena mengandung kata-kata keharusan seperti "shall" dalam butir-butir aturannya. ${ }^{15}$ Akan tetapi, apabila mengacu pada hukum yang bersifat mengikat menurut VLCT, maka obligasi juga perlu disertai dengan sanksi supaya pihak yang menanda tangani memiliki kewajiban yang lebih untuk mengikuti pasal yang telah ditentukan. Sementara itu, dalam AATHP tidak ada satu pasal pun yang mengacu pada sanksi terhadap pelanggaran AATHP ataupun sanksi dari ASEAN apabila tidak meratifikasi perjanjian ini. Tindak pelanggaran dilakukan sesuai dengan norma ASEAN yang

${ }^{13}$ Nick Flynn, Nicola Peart, "The Role of Political Agreement in a Legally Binding Outcome", European Capacity Building Iniciatives, diakses pada 28 November 2017, http://www.eurocapacity.org/downloads/TheRoleofPoliticalAgreementInALegallyBindingO utcome.pdf.

${ }^{14}$ Siddiq Ahmadi, "Prinisip Non-Interference dan Problem Effektivitas ASEAN Agreement on Transboundary Haze Pollution," Jurnal Hubungan Internasional 1, no. 2 (2012), diakses pada 28 November 2017, http://journal.umy.ac.id/index.php/jhi/article/view/336/384.

${ }^{15}$ Ibid, 13. 
lainnya yaitu konsultasi dan diplomasi informal. Hal inilah yang menjelaskan bagaimana Indonesia dapat bebas dari ratifikasi AATHP hingga tahun 2015.

Meskipun Indonesia terus mengirimkan kabut asap yang menyelimuti kotakota di Singapura dan Malaysia, kedua negara tersebut tidak pernah meminta pertanggung jawaban secara formal terhadap Indonesia atas kerugian yang telah dibuat terhadap kedua negara tersebut. ${ }^{16}$ Padahal, sejak dibentuknya Agreement on the Conservation of Nature and Natural Resources di tahun 1985, bisa saja Singapura dan Malaysia membawa kasus ini ke International Courts of Justice dan dapat memenangkan tuntutan terhadap kerugian yang diciptakan Indonesia akibat melanggar hukum regional yang ada. Salah satu alasan yang membuat Indonesia masih bebas melanggar kesepakatan ini adalah fakta bahwa perusahaan asal Malaysia yang dekat dengan pejabat penting negara tersebut merupakan investor terbesar kelapa sawit di Indonesia, sektor yang berkonstribusi banyak terhadap kebakaran hutan, sehingga Indonesia memiliki kekuatan politik untuk membujuk Malaysia agar tidak menuntut Indonesia mengikuti hukum regional yang telah ada. ${ }^{17}$

Elemen yang kedua adalah presisi, yaitu mengenai kejelasan dari butir-butir aturan yang ada, AATHP dinilai masih berada di tingkat yang rendah. ${ }^{18}$ Hal ini diakibatkan ketidak jelasan detail substansi dari penanganan masalah yang ada, sehingga memungkinkan terjadinya multitafsir dalam pengimplementasian. Sementara itu elemen yang ketiga adalah delegasi, dalam elemen ini dinyatakan bahwa perlu ada pihak ketiga untuk memastikan hukum internasional ini dapat diintepretasikan, diawasi, dan ditindak dengan semestinya. ${ }^{19}$ Dalam AATHP ini, ASEAN tidak menginstitusikan adanya pihak ketiga, meskipun terdapat satu pasal dimana dinyatakan pembentukan ASEAN Centre, akan tetapi fungsi lembaga tersebut hanya bersifat mengawasi dan mengatur koordinasi antar negara ASEAN, tidak memiliki fungsi yuridis. Fungsi yuridis sendiri tidak akan dapat diaplikasikan

\footnotetext{
16 Ibid, 3.

${ }^{17}$ Ibid, 3 .

${ }^{18}$ Ibid, 13.

${ }^{19}$ Ibid, 13.
} 
ke ASEAN Centre akibat tidak adanya pasal yang mengatur hukuman untuk pelanggaran kesepakatan ini.

\section{Konklusi}

Berdasarkan pemaparan mengenai sejarah pembentukan kerja sama regional untuk pengentasan kabut asap lintas batas negara hingga terbentuknya AATHP, terlihat bahwa ASEAN masih mengacu pada prinsip yang disepakati pada pendiriannya lima puluh tahun yang lalu. Hal ini terlihat jelas dalam substansi serta pengimplementasiannya dimana kesepakatan yang telah melewati serangkaian proses VLCT dan dapat dikatakan mengikat secara hukum ini ternyata dapat dikombinasikan dengan keterikatan secara politis yang dapat mengurangi tingkat legalitas dari kesepakatan ini sehingga terhindar dari pelanggaran norma ASEAN. Setelah mengetahui bahwa AATHP dan kerja sama sebelumnya tidak menciderai nilai, norma, dan identitas ASEAN, maka selanjutnya perlu dipertanyakan apakah norma tersebut masih perlu hadir dalam penanganan kasus kabut asap transnasional.

\section{Bibliografi}

"Indonesia Fire's and Haze Crisis." World Bank. Diakses pada 14 November 2017. http://www.worldbank.org/en/news/feature/2015/12/01/indonesias-fire-andhaze-crisis.

Ahmadi, Siddiq. "Prinisip Non-Interference dan Problem Effektivitas ASEAN Agreement on Transboundary Haze Pollution." Jurnal Hubungan Internasional 1, no. 2 (2012): 187-95. Diakses pada 28 November 2017. http://journal.umy.ac.id/index.php/jhi/article/view/336/384.

Ariadno, Melda Kamil. "Haze Pollution in ASEAN." Journal of Sustainable Development Law and Policy 2, no. 1 (2013): 1-35.

Barratt, Olly. "Haze episode cost Singapore estimated S\$700m last year: Masagos." Channel NewsAsia. 16 Maret 2017. Diakses pada 14 November 2017.

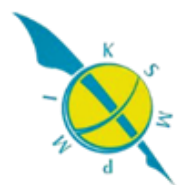


http://www.channelnewsasia.com/news/singapore/haze-episode-cost-

singapore-estimated-s-700m-last-year-masagos-8147924.

Bodansky, Daniel, Legally Binding versus Non-Legally Binding Instruments (August 31, 2015). Forthcoming in: Scott Barrett Carlo Carraro and Jaime de Melo, eds., Towards a Workable and Effective Climate Regime, VoxEU eBook (CEPR and FERDI). Tersedia di SSRN: https://ssrn.com/abstract=2649630.

Flynn, Nick., Peart, Nicola, “The Role of Political Agreement in a Legally Binding Outcome”, European Capacity Building Iniciatives, Diakses pada 28 November 2017 , http://www.eurocapacity.org/downloads/TheRoleofPoliticalAgreementInA LegallyBindingOutcome.pdf.

Heil, Angelika. "The 1997-98 Air Pollution Episode in Southeast Asia Generated by Vegetation Fires in Indonesia." International Forest and Fire News, no. 23 (2000). Diakses pada 14 November 2017. http://www.fire.unifreiburg.de/iffn/country/id/id 32.htm.

Heilmann, Daniel. "After Indonesia's ratification: ASEAN Agreement on Transboundary Haze Pollutions and Its Effectiveness as a Regional Enviromental Governance." Journal of Current Southeast Asia Affairs 34, no. 3 (2015): 95-121. Diakses pada 14 November 2017. https://journals.sub.uni-hamburg.de/giga/jsaa/article/download/907/914.

Kassim, Yang Razali. "A Haze Free ASEAN: Will the Vision Go Up in Smoke?" Diakses pada 20 November 2017. https://www.rsis.edu.sg/wpcontent/uploads/2014/07/CO13131.pdf.

Macarayan, Erlyn Rachelle K., Curley, Melissa and Western, Mark (2013). The Southeast Asian politics of natural resource use: impacts on food and health inequalities. In: APSA 2013: Australian Political Studies Association Annual Conference 2013, Perth, WA, Australia, (1-16). 30 September-1

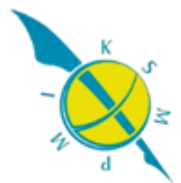


October, 2013. Diakses pada 14 November 2017. https://espace.library.uq.edu.au/view/UQ:328374.

Mushkat, Roda. "Constructivist Construction of International Enviromental Governances Regimes - The Southeast Asia Context." Merlbourne Journal of International Law 15, no. 1 (2014). Diakses pada 21 November 2017. http://www.austlii.edu.au/au/journals/MelbJIL/2014/8.html.

Tsai, Yu Tai. "The Emergence of Human Security: A Constructivist View." International Journal of Peace Studies 14, no. 2 (2009): 20-33. Diakses $\begin{array}{llll}\text { pada } & 14 & \text { November }\end{array}$ https://www.gmu.edu/programs/icar/ijps/vol14_2/TSAI\%20$\% 2014 n 2 \% 20 I J P S . p d f$.

Viotti, Paul, and Mark Kauppi. "Constructivist Understanding." In International Relations Theory, 276-326. New York: Pearson, 2010. 